\title{
Eduardo Pavlovsky: Teatro del estupor
}

\section{Carolina Muñoz P.}

\author{
Universidad de Concepción, Chile
}

E-mail: camunoz@udec.cl

\section{Resumen}

EI Teatro del estupor describe una escena teatral que explora subjetivamenteloslímites dela perturbación síquica en un movimiento de exorcismo colectivo. Los terrores sociales e individuales han de ser conjurados desde una realidad política/cotidiana concreta y transmitidos en un lenguaje (conjunto de los dispositivos escénicos de representación) teatral de choque, que en tal cualidad, forma partede la ética social de la furia. Esta perspectiva se basa en el estudio del texto teatral "Potestad" y de las principales prácticas vitales de $\mathrm{E}$. Pavlovsky; a saber, la crítica social y la terapéutica. Y en el cómo estas prácticas se entrelazan para la configuración y refiguración de las imágenes colectivas.

Palabras claves Poética del estupor, experimentación de sentidos, cuerpo social, victimización, violencia, paranoia, poder, potestad, apropiación, terrorismo de Estado, muerte, figura, figuraciones del cuerpo, unidades escénicas, macroescena.

\section{Abstract}

TheT heater of thestupor describes a theatrical scene that explores subjectively the limits of the psychic disruption in a movement of collective exorcism. The social and individual terrors should be conjure since a concrete political/routine reality and transmitted in a language (joint of the scenic devices of representation) theatrical of collision, that in such quality, form splits of the social ethics of the fury. This perspective is bases on the study of the theatrical text and of the main vital practices of E. Pavlovsky; to know, the social criticism and the therapeutic one. And in the how these practices are intertwined for the configuration and refiguration of the collective images.

Keywords: Poetic of the stupor senses, experimentation, social body, victimization, violence, paranoia, power legal, authority, appropriation, stateterrorism, death, figure, body figurations, scenic unity, macroescene.

Recibido: 10-12-2002. Aceptado: 28-10-2003.

E DUARD O PAVLOVSKY nace en Buenos Aires en 1931. Se ha desempeña- do como psiquiatra, actor, dramaturgo y director teatral. En su práctica de la psiquiatría se inclinó por el psicoanálisis, fue miembro de la Sociedad 
Psicoanalítica Argentina, de la cual se retiró por razones metodológicas. Además fue uno de los pioneros en la introducción del psicodrama como terapia clínica.

Su práctica teatral se manifestó desde muy joven, estudiando actuación y formando diversos grupos. En 1960 fundó, con Julio Lahier, el grupo y en ese grupo estrenó sus primeras piezas. Durante el último período dictatorial argentino, su obra Telarañas fue prohibida en Buenos Aires. Perseguido por los grupos paramilitares, se exilió en España. Volvió a la patria, para convertirse en el "más fiel intérprete de los temas que subyacen en el inconsciente colectivo (la memoria y el olvido, el castigo y el perdón, la cul pa y la venganza... )". Actualmente es considerado el autor argentino con más difusión internacional en vida.

Con la investigación que presento a continuación me propongo establecer unadeterminada perspectiva interpretativa que denomino teatro del estupor. Esta perspectiva se basa en el estudio de las principales prácticas vitales del autor, a saber, la crítica social, la terapéutica y la escena teatral y en el cómo estas prácticas se entrelazan para la configuración de las imágenes colectivas.

El Teatro del estupor describe una escena teatral que explora subjetivamente los límites de la perturbación síquica en un movimiento de exorcismo colectivo. Los terrores sociales e individuales han de ser conjurados desde una realidad política/cotidiana concreta y transmitidos en un lenguaje (conjunto de los dispositivos escénicos de representación) teatral de choque, que en tal cualidad forma parte de la ética social de la furia.

Asimismo, la idea de teatro del estupor es leída como una primera diagnosis contextual en el análisis del texto espectacular Potestad. Esta diagnosis contextual la defino como una propuesta reflexiva que pone en relieve las relaciones de connotación entre los signos sociales y sicológi cos para la lectura interpretativa del texto espectacular (pavlovskiano). La estética del "estupor" seinstala en tanto macroescena conceptual y describe la figuración de la violencia. A su vez, los diferentes elementos corporal es-materiales 0 unidades escénicas constituyentes van a dar forma a las figuraciones fundamentales: la figuración de la victimización, la figuración del poder y la figuración de la muerte. Las consecuencias de esta lectura se adscriben a una práctica individual de la memoria como acto reflexivo y terapéutico en una sociedad que demanda actos de exorcismo colectivo. 


\section{POETICA TEAT RAL DE EDUARDO PAVLOVSKY: ETAPAS}

\section{a) Estéticas experimentales}

Con la puesta en escena de La muerte de M argueritte D urás', el dramaturgo, actor y siquiatra Eduardo Pavlovsky recibe el 2001 en Buenos Aires el premio "Trinidad Guevara" al mejor autor dramático en un contexto sociopolítico, según el diario Clarín D igital del jueves 19 dejulio de 20012, "reina el pesimismo y la bronca", haciendo clara alusión a los desesperanzadores días en que está sumida la República de Argentina a raíz de la gran crisis económica de los últimos años.

En esta obra, siguiendo el comentario de la misma fuente con fecha 02 de agosto de $2000^{3}$, el director $D$ aniel Veronese pone en escena a un hombre envejecido, quien "frente a una mosca que agoniza, recuerda momentos de su vida como totalidades incompletas que sólo el presente, con su enorme carga de angustia y frustración, pueden completar"4.

Refiere Pavlovsky en la Revista Topía5: "Siempre pensé que uno de los factores que influyeron en la caída del socialismo real era un cierto tono de desprecio por los afectos y emociones existenciales delas personas", a propósito de la escritura del prólogo del libro G lobaloney del sociólogo norteamericano James Petras. En este texto el autor norteamericano hace un recorrido crítico de las nociones de globalización e imperialismo como argumento ideológico, que en términos sicológicos desmoraliza y debilita la capacidad crítica para la formulación de otras alternativas sociales posibles. Pavlovsky, a su vez, interroga: "D esde los gobiernos militares, ihemos transitado hacia la democracia o hacia un gobierno electoral neoautoritario?". Al respecto señala la pérdida de las "grandes tradicio-

${ }^{1}$ La muerte de $M$ argueritte $D$ urás, estrenada por el Teatro Babilonia con la dirección de D aniel Veronese (julio, 2001), web site http://www.autores.org.ar/Epavlovsky

${ }^{2} \mathrm{~N}$ ota de $\mathrm{M}$ abel Itzcovich, Clarín Espectáculos, web site http://www.laguia.clarin.com

${ }^{3}$ Crítica teatral de Ivana C osta, C larín Espectáculos, web site http://www.laguia.clarin.com

${ }^{4}$ La pieza estructurada como monólogo contrasta con una escen ografía en la cual aparecen "una pared sucia, gris, un sillón negro y un tubo fluorescente". La escena propuesta sin duda es un recurso de exploración sicosocial. La mosca como personaje agónico escenifica la insignificancia, śntoma de una identidad indiferenciada, sin sentido vital; mientras lo humano -en la actuación de Pavlovsky- habla desí mismo, consigo mismo de la vida, la muerte, la agonía. Así se quiebra el esquema, el logos occidental se animaliza y se vuelve insignificante. Lo animal se abstrae y adquiere un nombre antes de la muerte.

${ }^{5}$ Prólogo de Eduardo "Tato" Pavlovsky al libro Globaloney de James Petras, revista Topía, web site http://www.topia.com.ar 
nes críticas de la mejor intelectualidad de las universidades de América Latina", cuya recuperación va a estar dada por la comprensión de los nuevos movimientos sociales de resistencia en Latinoamérica.

En este contexto ideológico, el dramaturgo junto al escritor D avid Viñasy el mismo Jaime Petras en una conferencia realizada en la Sociedad Argentina de Escritores y organizada por la revista $H$ errami entas ${ }^{6}$, profundizan el tema social con "agudos análisis sobre los intelectuales y la izquierda" que, según la comisión directiva de la revista, "asume sin un análisis crítico el nuevo lenguaje imperial, fijando especialmente la atención hacia las nuevas formas en que se manifiesta la lucha contra la redoblada barbarie capital ista".

Pavlovsky llama la atención sobre tres temas fundamentales: la influencia de la globalización en los intel ectuales de izquierda, la existencia de los movimientos micropolíticos y la crítica al marxismo en tanto "la ausencia de la necesidad de la convulsión de la subjetividad". Temas que el mismo autor resume como sigue: "Evidentementela subjetividad que produce la globalización ha marcado una línea de inexorabilidad frente al combate contra el poder. No sé cuando ha existido en la humanidad un sistema de tal nivel de explotación y de miseria".

Un escenario distinto, cuya puesta en escena es la realidad misma y la construcción del espacio dramático está dado por la micropolítica o espacios de resistencia cultural. "M icropolíticas éticas"7 titula Pavlovsky un artículo publicado por la revista L ote, en la cual perfila con clara virtud dramática lo social:

Caminos por los bordes - micropolíticas éticas-, estéticas experimentales donde se jueguen la posibilidad de creación de nuevos territorios existenciales, nuevas búsquedas del ser en los grupos - nuevos acoplamientos-, nuevas producciones de máquinas deseantes que permanentemente intenten escapar de los aparatos de captura del poder y puedan crear nuevas subjetividades, nuevas maneras diferentes de pensar el mundo. Nuevas formas de experimentación y de búsqueda de nuevos lenguajes. Ruptura de la escenografía de la pura representación. Ese es el núcleo del Resistir H oy. N o simple oposición sino textura de una resistencia con nuevos sentidos. La riqueza de fenómenos políticos como El C ordobazo - 0 M ayo del '68-, no se pueden entender desde la simple explicación delarepresentación política sino como "acontecimientos" que fueron desvíos de la historia, y que no tenían una clara representación.

${ }^{6}$ Conferencia "El lenguaje imperial, los intelectuales y la izquierda". (James Petras, Eduardo Pavlovsky y D avid Viñas), H erramientas, web site http://www.herramienta.com.ar

7 Pavlovsky, Eduardo: “M icropolíticas éticas", revista Lote (agosto de 1998), № 14, web site http://www.revistalote.com.ar 
Si una nueva oportunidad de la humanidad está en el devenir revolucionario, Pavlovsky integra en su obra, crítica social y subjetividad de invención. Una escena teatral en la cual la pregunta por el "quéhacer" esel eje dominanteen tanto pregunta por la identidad estética cultural como por el espacio escenográfico. Participamos, entonces, de la escenificación de la violencia, "el microfascismo cotidiano", como se refiere a su práctica teatral el autor. Yo lo llamo teatro del estupor, un teatro entre la perturbación y la furia: estética de la perturbación, ética social de la furia8.

A propósito de lo que D eToro llama "pura estética del placer", es decir, "poética teatral inmanentemente rizomática en la cual el lenguajeteatral es recodificado en sus aspectos semánticos y sintagmáticos y en su artificio discursivo", nosotros hemos denominado "teatro del estupor" a una escena teatral que explora subje tivamente los límites de la perturbación síquica en un movimiento de exorcismo colectivo. En éste los terrores sociales e individuales son conjurados desde una realidad política/cotidiana concreta y transmitidos en un lenguaje (conjunto de los dispositivos escénicos de representación) teatral de choque (duro, fuerte) que forma parte de la ética social de la furia, como ya lo dijimos.

En el tránsito de social a lo sicológico, Pavlovsky en su práctica sicoterapéutica ha generado nuevas al ternativas en el ámbito del psicoanálisis y el psicodrama. En el texto La multiplicación dramática: un quehacer entreel artey la si coterapia ${ }^{9}$ de 1989, junto a Hernán Kesselmann se enuncian los pilares de esta práctica

${ }^{8}$ Un acercamiento etimológico al término dado, puede sernos útil en la construcción del sentido requerido. Se propone un primer acercamiento: Estupor, tomado del latín stupidus (aturdido, estupefacto, estúpido), derivado de stupere (estar aturdido) (C oromiras, Joan, D iccionario crítico etimológico de la lengua castellana. M adrid, Ed. Gredos, 1976). Por otra parte, en la Real Academia Española selee lo siguiente: "D isminución dela actividad delasfunciones intelectuales, acompañada de cierto aire 0 aspecto de asombro o de indiferencia".

Para el término de "perturbación" se lee indistintamente: "inmutar, trastocar el orden y concierto, o la quietud y el sosiego de algo o de alguien"; el término "furia" va a significar: "ira exaltada". A su vez el término "ira" significa: "pasión del alma, que causa indignación y enojo". Ahora bien, la noción de teatro del estupor como estética de la perturbación y ética social de la furia se construye semánticamente privilegiando los siguientes sentidos: estupefacto - aspecto de asombro - trastocar el sosiego - indignación y enojo, con los cuales permiten generar la definición que sigue: "estupefacción intelectual, acompañada de aspecto de asombro en una percepción estética de la realidad fundada en el trastocamiento del sosiego, provocando la indignación y el enojo social como respuesta ética".

${ }_{9}^{9}$ Pavlovsky, Eduardo: La multiplicación dramática: un quehacer entre ed artey la sicoterapia, web site: http://www.campogrupal.com/textos.html 
sicodramática ${ }^{10}$ : La multiplicidad de sentidos' ${ }^{11}$ como principio teórico y la multiplicación dramática como su "encarnación en escenas". Una dramatización inicial de un paciente es denominada "texto escrito", su puesta en escena, "producción dramática", las resonancias en el grupo terapéutico, "texto dramático". Así, van a ser metabolizados dos procesos concomitantes: el clínico psicodramático y el estético; una curación basada en el tránsito de "Io siniestro a lo patético" y deéste "alo maravilloso", en la medida quesetransforma "I a síncopa de pausas, velocida des, articulaciones y conexiones de los ritmos vinculares", finalmente "transformael acto de salir a multiplicar antes quela actividad pensanteo la obsesión por entender el origen de las historias".

La multiplicación dramática como superación del psicoanálisis edípico, lo entendemos como uno de los procesos creadores del autor, en un sistema conceptual perfectamente consistente: la crítica social, la terapéutica, la escena teatral.

Con anterioridad al desarrollo de la noción de multiplicación dramática, Pavlovsky estableceen el análisis del desarrollo de las sesiones de psicoterapia de grupo, estrechas relaciones entre los acontecimientos sociopolíticos del período dictatorial argentino y su incidencia en la producción imaginaria de estas sesiones. En su artículo "Lo fantasmático social y lo imaginario grupal"12 el autor se interroga sobre una cuestión fundamental: "¿Existía alguna singularidad específica del proceso inconsciente grupal y su relación con el inconsciente social?", la respuesta es entregada en la escritura dramática de una sesión ejemplar depsicodrama que se basa en la práctica de la memoria, "la curación es recordar para no repetir", "si no recuerdo repito", "si repito actúo". Luego aclara, "el grupo funciona como un sensor delas individualidadesmás transgresoras delanorma social interiorizada".

Junto a lo anterior, se incorpora la noción de "pacto", definida en términos escénicos: "Algo se torna innombrable (en el grupo)". Cada participante de la sesión va a actuar según su "fisic du rol", generando el grupo de psicoterapia un argumento extraído de su propio inconsciente social (muerte, dolor, asesinatos,

\footnotetext{
${ }^{10}$ a) Psicoanálisis grupal: pasaje a lo grupal y la producción de subjetividad singular y colectiva como nivel de análisis. b) Concepciones fundantes epistemológicas: el saber, el curar, el crear (la transformación, el cambio). c) M étodos de investigación: noción de "resonancia”. Pavlovsky, op. cit.

${ }^{11 S e}$ define como sigue: "En la escena original están inscriptas las posibilidades de las multiplicaciones grupales"; "Ia escena original funciona como una obra abierta"; "Io más individual se funde en la producción dramática". Pavlovsky, op. cit.

${ }^{12}$ Artículo basado en un trabajo titulado Psicoterapia en situaciones excepcionalesen el cual e autor sostiene: "intentábamos caracterizar algunos fenómenos clínicos y de dinámica grupal que habíamos observado en nuestros grupos durante el lapso 1976-77, período caracterizado por la represión política por todos conocido" (Se alude al Gobierno militar periodo 19761983). Pavlovsky, Eduardo y Armando Bauleo, Psicoterapia en situaciones excepcionales, 1976, web site http://www.campogrupal.com
} 
desapariciones, traidores, persecución, etc.) para ser representado por cada uno de los integrantes-personajes, los que hablan desde su inconsciente social.

La recreación del inconsciente social mediante la invención de personajes que apelan a una fantasmática social se concreta en un proceso de exorcismo en el cual "circulamos el terror de la convivencia con el monstruo. Lo recreamos ante nosotros para exorcizarlo". Finalmente el autor sostiene que la psicoterapia se basa en el argumento teatral, es decir, "intercambio de máscaras", para pade cer y recrear grupalmente los "terrores infinitos" del inconsciente social.

Uno delos materiales fundamentales en la escritura reflexiva de Pavlovsky es la relación generada entre las nociones "terapia" y "existencia", las cuales van a titular el texto escrito en 1982 y del cual el autor refiere: "Son reflexiones sobre la historia de la psicoterapia de grupo y del psicodrama", "Son reflexiones sobre mi vida".

Terapia y existencia es una indagación puramente subjetiva sobre las propias influencias personales - "dialéctica de la persona"- y de los contextos sociales - "dialéctica de la situación"- quellegan a configurar la "silueta de este terapeuta que hoy soy yo, y no otro, cuando estoy trabajando en un grupo de terapia", refiriendo a la autogénesis plavovskiana. D elas cinco zonas autogenéticas queel autor reconoce, voy a detenerme brevemente en "Experiencias personales y artísticas"13. En las profundidades de la práctica teatral van a surgir las reflexiones sobre la perspectiva grupal y el proceso de creación de personajes en tanto "ruptura del propio narcisismo", "procesos de duelos emocionales" y "reencuentros con aspectosíntimos disociadosy reprimidos". Si aplicamos estas reflexiones a la práctica terapéutica y a la teatral, se hace evidente el sentido libertario en tanto "exorcización de lo siniestro", donde cohabita una cualidad de exteriorización patética (creatividad o psicodrama) y una cualidad lúdica de concretización.

Al respecto Pavlovsky señala: "Porque no se puede hacer de un torturador, si uno no se pone en contacto con su propio torturador (Sr. Galíndez)". "Porque no se puede hacer un homosexual si uno no se pone en contacto con su propia homosexualidad (Atendiendo al Sr. Sloane)". "Porque no se puede hacer un padre débil y sometido si uno no se pone en contacto con su propia debilidad y sometimiento (Telarañas $\left.{ }^{14}\right)^{\prime \prime 15}$.

${ }^{13}$ Aquí es determinante la actividad actoral de Pavlovsky, la que comienza a estudiar a partir de 1960 junto a Alejandra Boero, Pedro Asquini y Conrado Ramonet, tres figuras importantes del teatro independiente argentino.

${ }^{14}$ Esta pieza teatral va a escenificar la perversidad vincular en la familia; tres personajes (e padre, la madre y el pibe) desconstruyen la idealización burguesa-cristiana sobre el cuadro familiar y lo que vemos a cambio son roles filiales disfuncionales, patológicos. D e un padre "débil y sometido" y de una madre sádica concluimos a un hijo muerto, asesinado macabramente en una horcaregalo.

${ }^{15}$ Pavlovsky, Eduardo: Terapia y existencia. Buenos Aires: Ediciones Búsqueda, 1982. 
Así, cuando la silueta del ser deviene práctica creativa y proceso terapéutico, nos enfrentamos al "quéhacer" pavlovskiano: "un nuevo modelo de aprendizaje de la posibilidad de comprender la conducta humana"16, en relación con la experiencia ideológica capaz de especificar dialécticamente esta conducta.

\section{b) Coágulos textuales del fenómeno psicosocial}

Algunas de las líneas de reflexión del texto Reflexionessobreel proceso creador del año 1975 son aquéllas relacionadas precisamente con el desarrollo de la noción de "pensamiento dialéctico liberador" que estructura los dos núcleos temáticos de éste; por una parte están las reflexiones sobre creatividad y psicodrama en las que se plantea un método de superación yoica basado en técnicas contrafóbicas que permiten "elaborar y aceptar los aspectos más rechazados de uno", que promueven la "desintegración" de las estructuras narcisistas más rígidas. Por otra parte, están presentes las reflexiones sobre la creatividad en el teatro, las que a través de comentarios sobre Ionesco, Beckett, Sartre, Artaud, Grotowsky y su propia práctica teatral, se concretan en "coágulos" textuales en la medida que el proceso deescritura dramática se mediatiza por la vivencia delo incomunicable, de lo irrevelado, de la soledad, etc.

Así, entendemos por pensamiento dialéctico a aquellos fenómenos de identificación introyectiva y deidentificación proyectiva quees liberador en tanto permite el traslado del yo desde la identificación narcis sta hacia la zona del fuera de sí mismo. Pavlovsky señala al respecto:

Escribo lo que no puedo compartir, lo que mis gestos y mis palabras no saben expresar. Aquello que quedó enquistado en mi desesperación, algo que me violenta. (...) $\mathrm{M}$ is personajes traducen mi mal. $\mathrm{N}$ o hay gestos reparadores en mi teatro; hay odio, perversión, resentimiento, violencia abismal. No hay primera intención de comunicar nada a nadie. Es un vómito de desesperanza, de terror, el peor de los miedos ${ }^{17}$.

"Algunos conceptos sobre el teatro de vanguardia" escrito en 1966, siguiendo la idea de Q uiroga en Teatro del ' 60 , aparece citado como formando partedel "real ismo reflexivo"18, junto a G risel da Gambaro y cuyas matrices de teatralidad

${ }^{16}$ Pavlovsky, Eduardo: Reflexiones sobreel proceso creador. Buenos Aires: Ediciones Búsque da, 1982

${ }_{17}$ Pavlovsky, op. cit.

${ }^{18}$ Noción de $\mathrm{O}$ svaldo Pellettieri citado por $\mathrm{O}$ svaldo Q uiroga en "El teatro de Eduardo Pavlovsky", Eduardo Pavlovsky. Teatro del '60. Buenos Aires: Ediciones Letra Buena, 1992. 
se encuentran en el Teatro del Absurdo ${ }^{19}$ por una partey en el "Grotesco" 20 , por otra, las que van conformar el "Teatro de Vanguardia en Argentina"21. El texto antes mencionado es la primera referencia autorreflexiva del autor que se publica junto a $M$ atch y La cacería, las primeras piezas teatrales de Pavlovsky en las cuales lo histórico y lo social se van a perfilar como determinantes.

\section{c) El espíritu de Beckett y de Ionesco}

La producción dramática de Pavlovsky se inicia con la escritura de Somos, La espera trágica, Acto rápido entre otras. $\mathrm{H}$ ay en éstas, según Zunino ${ }^{22}$ una gran influencia del "espíritu de Beckett" y cuyo tema es la incomunicación en tanto superposiciones del silencio, de los gestos y de las palabras. Q uiroga ${ }^{23}$, en cam-

${ }^{19}$ Seguimos a C ontreras, quien al respecto señala: “El absurdo como categoría de descripción literaria se define en la mayoría de los estudios por las siguientes características. Se presenta como una descomposición del lenguaje en diferentes modalidades tendientes a la no significación basada en la reducción de la capacidad conceptual y significativa del diálogo. El humor y la descomposición de los hábitos verbales son usados para criticar un estado de cosas existentes en la sociedad". C ontreras M arta: Griselda Gambaro. Teatro de la descomposición, C oncepción: Ediciones U niversidad de Concepción, 1994.

${ }^{20}$ Selee en el texto antes citado: "grotesco es lo queen un determinado momento un grupo entiende por tal en su relación con los objetos artísticos, pero también lo que trabaja desde el interior de un texto, como parte de un diálogo, para alcanzar un nuevo estadio del desarrollo del medio artístico de que se trate. El motivo o tema aislado carece de sentido y la presencia de un monstruo 0 animal ominoso es un momento de una unidad espacio-temporal articulada de acuerdo a las condiciones del tiempo en cada caso". Contreras, op. cit.

${ }^{21}$ Para Griselda G ambaro el teatro de vanguardia es aquel en que "cada pieza responde a una regla del juego, y aunque se deje al público el trabajo de descifrar el sentido final de la pieza, las reglas del juego deben ser dadas con claridad". Citado por Contreras, op. cit.

Para Pavlovsky el teatro de vanguardia es "un teatro primordialmente de búsqueda. Es un teatro que dice 'hacia' y que intenta conectarnos con aspectos absolutamente'reales' de nuestra personalidad. (...) el teatro de nuestra soledad, el que nos hace hablar en el idioma de nosotros, con nosotros y no de nosotros, con los otros. (...) intenta expresarse en un lenguaje distinto, buscando la síntesis a veces a través de la imagen y no dela palabra, donde lo simbólico y lo real se fusionan dando una nueva dimensión". Pavlovsky, Eduardo: Eduardo Pavlovsky. Teatro del '60. Buenos Aires: E diciones Letra Buena, 1992. En el texto Reflexi ones sobreel proceso creador, el autor corrige: "Interpretaba la trama argumental sólo como un fenómeno onírico, descartando la dialéctica autor, persona, sociedad. N o incluía la posibilidad de un proyecto superador delas contradicciones del hombre desesperado frente a su soledad e incomunicación". Pavlovsky, op. cit.

${ }^{22}$ Zunino, Pablo: "Las heridas del horror", Teatro argentino contemporáneo. Antología. España: Fondo de Cultura Económica, 1992.

${ }^{23}$ Q uiroga, O svaldo: "El teatro de Eduardo Pavlovsky", Eduardo Pavlovsky. Teatro del '60. Buenos Aires: Ediciones Letra Buena, 1992, p. 10. 
bio, ve una espesa intertextualidad con las obras de Ionesco, sobre todo en la configuración de los personajes de los cuales señala: "Las conversaciones de los personajes son tan intrascendentes como las que mantienen las criaturas de $L a$ cantante cal va". Así, observamos un teatro que deja de manifiesto la ruptura en la abolición de las nociones lógicas de tiempo y espacio y en el uso del humor, humor negro ${ }^{24}$. Todos procedimientos del Teatro del Absurdo ${ }^{25}$, matriz conceptual del quehacer artístico de Pavlovsky.

\section{d) Teatro de estados: teatro del estupor}

Pavlovsky perfila la teatralidad desarrollada como un teatro de estados, es decir, un teatro "que es puro devenir: bloques de intensidad. Son pedazos de vida, fragmentos, como manchas, de ésas que Bacon tiraba en la tela para que de ahí surgiera la forma". O bservamos una estética basada en la exasperación, denominada por el autor como "realismo exasperante", el cual se funda en la realidad, pero "todo está como crispado". La crispación entendida como "contar las cosas desde arriba", es decir una variación de las perspectivas o puntos de vista de la acción, a partir de las cuales es posible resolver los conflictos en escena con el uso del grotesco, del humor negro como elemento relacionante entre lo real y las patologías que subyacen a los procesos psicosociales inherentes a lo humano. Génesis teatral asentada en una "zona de misterio del mundo", en la cual vemos una relación puramente perceptual entre el autor y su tiempo y desde la cual los dispositivos ideológicos de denuncia (acción) son refocalizados hacia una actitud de la "perplejidad", es decir, "desde la incertidumbre de un balbuceo"26.

Para una descripción del cuerpo dramático a ser examinado ${ }^{27}$ he elegido la

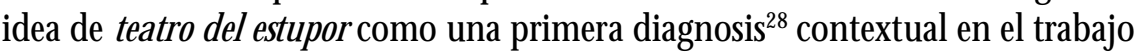

${ }^{24} \mathrm{C}$ ontreras define el humor negro como un procedimiento asociado al grotesco. Contre ras M arta: Griselda Gambaro. Teatro de la descomposición, Concepción: Ediciones Universidad de Concepción, 1994.

${ }^{25}$ Pavisal definir teatro del absurdo señala: "Es preciso distinguir entre los elemento absurdos en el teatro y el teatro absurdo contemporáneo. En el teatro, designaremos como absurdos los elementos que no conseguimos situar en su contexto dramatúrgico, escénico, ideológico. Elementos de este tipo aparecen en formas teatrales muy anteriores al absurdo de los años cincuenta. El acto de nacimiento del teatro de absurdo, como género o tema central, lo constituye La cantantecalva de lonesco (1950) (... )". Pavis, Patrice: D iccionario del teatro. D ramaturgia, estética, semiología. M adrid: Editorial Paidós, 1998.

26 "Un teatro de incertidumbres" (entrevista), Clarín Cultura y N ación (13 de agosto de 2000), web site http://www.laguia.clarin.com

${ }^{27}$ M e refiero al texto dramático "Potestad" a ser descrito y analizado en el siguiente capítulo.

${ }^{28}$ N oción desarrollada por Contreras: "D iagnosis significa etimológicamente conocer, dis- 
lector/espectador, en tanto propuesta reflexiva que poneen relieve las relaciones de connotación entre los si gnos socialesy sicológi cos para la lectura interpretativa del texto espectacular (pavlovskiano). En el teatro del estupor se ha de privilegiar una estética de "la perturbación", en tanto eje organizador de la escena teatral pavlovskiana. Es decir, se establece una macroescena conceptual que nos va a permitir abrir paso

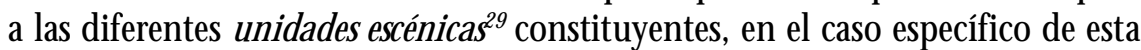
investigación, del texto dramático "Potestad".

\section{POETICA DEL EST UPOR EN POTESTAD ${ }^{30}$ : AN ALISIS DEL TEXTO ESPECTACULAR}

El autor concibió la escritura de esta obra en forma paroxística (tres horas) y de inmediato se propuso su puesta en escen $a^{31}$, a sólo dos años del fin del G obierno militar en Argentina y de la subsiguiente denuncia del terrorismo de Estado ejercido sistemáticamente por éstos durante el período 1976-1983². Leo esta

cernir. En el sentido médico es el conocimiento diferencial de los signos de las enfermedades. D iccionario de la Real A cademia Española, 1984". "El concepto de diagnosis literaria refiere a la manera de entender la literatura como conocimiento 0 análisis. Es decir, como un juego de representaciones que en su disposición y combinatoria son una proposición de comprender la realidad humana poniéndole nombre a las zonas oscuras o desconocidas, a los problemas no resueltos". Contreras M arta: G risel da Gambaro. Teatro de la descomposición, Concepción: Ediciones Universidad de Concepción, 1994.

${ }^{29}$ N oción desarrollada por C ontreras: "La unidad escénica está constituida por los objetos materiales y la disposición de ellos en el escenario espacial y/o verbal eincluye el factor tiempo. Esto significa que el mismo espacio con los mismos objetos en otro tiempo constituye una unidad escénica diferente". Contreras, op. cit.

${ }^{30}$ Todas las citas del texto dramático "Potestad" pertenecen al siguiente texto: Teatro argentino contemporáneo. Antología. España: Fondo de Cultura Económica, 1992, pp. 781-795.

${ }^{31}$ Junto al director Norman Briski en 1985 en el Teatro del Viejo Palermo.

32 Ivana C osta, en una nota publicada en el diario Clarín el sábado 24 de marzo de 2001 comenta: "Cuál fue el efecto de la dictadura sobre el teatro y la cultura teatral de los argentinos no es sencillo de resumir, en parte porque sus consecuencias son todavía motivo de crisis y de polémica. Pero un ligero repaso de la situación de algunos de los autores más importantes de los 70 sirve para entender la brecha que se abrió entonces entre la literatura dramática, la percepción de la realidad y el público. H acia 1977, Griselda Gambaro, Juan Carlos Gené, Carlos G orostiza, Eduardo Pavlovsky y 0 svaldo D ragún, entre otros, habían sido prohibidos, acallados, amenazados o estaban ya exiliados. Los que se habían quedado - Roberto Cossa, Carlos Somigliana, Ricardo Talesnik, Ricardo M onti, por ejemplo- estaban sometidos por idéntica persecución ideológica y, en muchos casos, su propia vida era objeto de amenaza. Los actores, directores y escenógrafos no gozaban de mejor suerte. Tanta opresión terminó por provocar una respuesta. Sellamó Teatro Abierto y fue, tal vez, el episodio de resisten cia cultural más significativo de todo ese período". Costa, I vana: "Teatro: inteligencia y coraje para combatir la censura: una abierta resistencia", Clarín, web site http://www.laguia.clarin.com 
escritura dramática como "clave elaborativa" ${ }^{33}$, que instala en un espacio-tiempo tridimensional las relaciones sociales entre violencia, poder y muerte. Siguiendo a Avelar ${ }^{34}$, perspectivizarélos signos ideológicos de la sociedad argentina como constitutiva de un "núcleo conspiratorio" donde subyace la "ficción política" en oposición a la "realidad política". Es decir, una sociedad articulada sobre discursos sociales de carácter más ficcional que real.

M e propongo tratar la poética de Pavlovsky desde la diagnosis: puesta en relieve de las relaciones de connotación entre los signos sociales y psicológicos para la lectura interpretativa del texto espectacular en tanto unidades escénicas que contienen elementos corporales-materiales determinantes en la puesta en escena de la violencia como macrofigura dramática.

Así, en el carácter corporal-material de los personajes y en su calidad de figuras dramáticas se establece la rel ación social entre ellos (gestusfundamental) en función de una escena subjetiva temida ${ }^{35}$, que enmarca su apariencia, desplazamientos (movimiento corporal-facial), configura sus comportamientos (gestualidad) como cuerpo psicosocial violentado por un asesino que es víctima de sus propios fantasmas psíquicos.

El texto dramático "Potestad" se construye sobre la relación entre dos personajes: El H ombre y Tita. Una escena material única se articula en diferentes niveles de sentido: a) procedimiento monologal que referenciala historia, motivaciones y acciones del personaje en escena; $b$ ) el tiempo dramático dispone la historia de manera que la escena inicial remite a un episodio anterior al que acaba deser evocado (flash-back); c) el espacio teatral (dramático/escénico) construyeun espacio interior fantasmagórico; de manera quela visualización escénica implica la contemplación del yo íntimo del personaje y sus fantasmas; y se de termina la unidad escénica única, en la cual "se desplazan las figuras y ocurren las acciones que se ordenan bajo la categoría de situación"36.

${ }^{33}$ Kesselman, Hernán y Eduardo Pavlovsky: La multiplicación dramática. Buenos Aires: Editorial Galerna, 2000

${ }^{34} \mathrm{Avelar}$ I Idelber: “U na lectura al egórica de la tradición argentina”, La ficción postdictatorial y el trabajo del duelo. Santiago: Editorial Cuarto Propio, 2000, p. 130.

${ }_{35}$ Pavlovsky, Eduardo: La multiplicación dramática. Un quehacer entreel arteyla sicoterapia, web site http://www.cam pogrupal.com

${ }^{36} \mathrm{C}$ ontreras, M arta: G riselda G ambaro. Teatro dela descomposición, Concepción: Ediciones Universidad de Concepción, 1994. 


\section{Unidad escénica única}

La escena está dispuesta por dos sillas y el cuerpo de un hombre que se desplaza indistintamente entre-sobre-adelante-atrás de éstas. En este desplazamiento gestual se genera otro desplazamiento de carácter interno, en el cual el cuerpo se integra a través de la enunciación discursiva para proponer otra realidad a ser escenificada. Esta escena única se realiza en tres situaciones dramáticas.

\subsection{La silla-sentarse}

La primera situación dramática se articula en relación con los múltiples despla zamientos queEI H ombre gestualiza en escena y de los movimientos de interioridad y exterioridad que los desplazamientos propician:

Sábado, tres y media de la tarde. Yo estoy sentado acá (Señala la silla derecha) Ana M aría, mi mujer, está sentada acá... (Señala la silla izquierda). M ás o menos a un metro treinta, un metro treinta y cinco del vértice de la pata izquierda del sillón, está sentada mi hija Adriana).

La posición física de cada uno de los miembros de la familia es importante en la medida en que la posición física describe. Evoca, sugiere la relación entre los miembros de la familia, el tipo de vínculo entre ellos (...)

Posición mía de este sábado tres y media de la tarde (Se sienta en la silla derecha y coloca su pierna derecha en ángulo agudo y la izquierda en ángulo recto).

El personaje se ha obsesionado con el estudio de la proxémica familiar para reinstaurar o reestructurar sus vínculos, los que han sido afectados por el paso del tiempo, el no deseo sexual, la proyección parental en la hija, entre otras causas. En este sentido, el cambio de estatuto de personaje a figura se inicia y la proxémica se constituye como espacio figurativo de la soledad.

La figura concretada va a constituirse como una figura bifronte. Para esta primera situación es la figura de la víctima, la que se presentifica y nos interroga como lector/espectador sobre un episodio traumático, afecto perdido o un doIor padecido que vuelve y se materializa como cuerpo.

La noción de "víctima", desde una perspectiva psicoanalítica, sed efine como formando parte de los procesos psicopatológicos de un individuo, en el cual "la pulsión de muerte que no destruye al sujeto debe proyectarse afuera. Pero de penderá de cómo éste se relaciona con la cultura de la que forma parte para que el sentido de la destrucción y muerte que coloque afuera implique o no una 
solución"37. En este sentido, el accionar de esta pulsión de la muertese manifestará después en la violencia contra el otro, el suicidio, las adicciones, las depre siones, las personalidades limítrofes, los procesos de despersonalización, etc. ${ }^{38}$

Asimismo, para una diferenciación de los síntomas, remito a la noción de pulsión parcial, de la que la pulsión de crueldad (activa-pasiva) es determinante en la actitud social del sujeto. Además, el elemento de crueldad causa en la libido una serie de transformaciones en los afectos: "transformación del amor en odio, de emociones tiernas en movimientos hostiles" ${ }^{\prime 39} \mathrm{y}$ forma la sintomatología de la paranoia.

Si leemos la figura propuesta como la escenificación de la victimización en su estado subjetivo eindividualizado, podemos significar, en una primera ap roximación, que los vínculos familiares (constituyente medular de la organización de la personalidad) han desaparecido y sólo queda un sujeto violento, suicida, adicto, depresivo, limítrofe, entre otros. Y en su correlato social-ideológico, la víctima es un cuerpo social paranoico (estrato sociocultural, un estatuto legal: civil/militar, un relato ideológico: marxistas/no-marxistas, etc.), que a través de los mecanismos de terror y muerte se defiende de ciertas "cosas" que no puede tolerar. El desplazamiento del yo-social implica la desapropiación de un "contenido incompatible con la identidad que el sujeto se reconoce" ${ }^{\prime \prime 0}$

\subsection{La puerta-el timbre-abrir la puerta}

Suena el timbrey El Hombre al abrir la puerta es interpelado por dos desconocidos que le preguntan por Adriana, la hija. Los desconocidos son propuestos como "gentebien"; es decir, clase alta; la que sería poseedora de una gestualidad particular, una inflexión de voz propia y una superioridad psicológica tal.

Sábado tres y media de la tarde... a eso más o menos de las cuatro y cuarto sonó el timbre de mi casa, cosa que me alegró profundamente porque me permitió saltar de la silla elegantemente... (... ) abrí la puerta... aquí, abrí la puerta, aquí... y aquí aparece un señor bien vestido, un tipo bien, difícil de imitar, quiero decir, tienen un movimiento muy lindo decaderay de hombro, angular, un tipo bien, bien vestido, elegante, jugador de polo (... ). Un movi-

${ }^{37}$ C arpintero, Enrique: "La cultura del mal-estar: El sujeto es el planeta", Regi stros de lo negativo, Topia, web site http://www.topia.com.ar

${ }^{38}$ Carpintero, op. cit.

${ }^{39} \mathrm{~K}$ aufmann, Pierre (director): Elementos para una enciclopedia del psicoanálisis. El aporte freudiano. Buenos Aires: Paidós, 1996.

${ }^{40} \mathrm{~K}$ aufmann, op. cit., p. 373. 
miento muy lindo con las manos hacen, una arriba de la otra, así, no, muy fino... y una miradita... con la vista, aś, no... (Imita el tono de la clase alta argentina) ¡Buenas tardes, señor!, me dijo. M equedémedio fascinado, lo miré, ojos claros, bien vestido, saco azul, pantalón gris, "iBuenas tardes, señor! Yo quisiera hablar con su hija Adriana, diez minutitos, diez minutitos nada más... quisiera hablar con su hija Adriana, diez minutitos... D espués vamos a hablar con usted y su mujer, ieh?

A través del recorrido proxémico que el personaje realiza se sintomatiza una práctica social, que sólo es comprensibleen relación a los procesosideológicosque subyacen bajo la interpelación con la que dos desconocidos irrumpen el núcleo familiar y detentan un determinado poder, como es el de hablar con la hija. Antes dereferir procesosideológicos antes mencionados, evidenciaréel tiempo dramático cuyo procedimiento analéptico es relevante en esta situación dramática.

Al iniciar la diagnosis, definí el tiempo dramático como remitente: la escena inicial remite a un episodio anterior al que acaba de ser evocado. Para la primera situación dramática, el tiempo analéptico es introducido bajo la forma de leitmotiv, se reiteran las nociones temporales obsesivamente para situar un acontecimiento que desconocemos como lector/espectador:

Sábado, tres y media de la tarde. Yo estoy sentado acá (... )

Si el sábado tres y media de la tarde, suena el teléfono el timbre (... )

Sábado tres y media de la tarde... a eso más o menos de las cuatro y cuarto sonó el timbre de mi casa. (...)

En esa situación dramática se nos revela un nuevo aspecto de este acontecimiento. El Hombre en sus desplazamientos hacia la interioridad, protege su integridad, se defiende de la agresión de los desconocidos con la materialización corporal de la dialéctica entre un "antes" y un "después". De esta forma, el tiempo dramático adquiere la forma de flash-back y el personajenos hace partícipes de una "época de antes":

(... ) entonces rápidamente me dijo: "Por favor, señor, vamos a aclarar bien las cosas, que no estamos en la época de annntes, ipor favor señor, tranquilícese que no estamos en la época de antesss! iiAntesss!!". Como yo soy disléxico y pierdo el sentido del tiempo y del espacio creo que, ahora me doy cuenta, que "Antesss, Annntesss", se refería a un período anterior, un período que era anterior, y después, viene el futuro. Pero como yo soy disléxico, me quedé con el Annntesss... M e enfrentéaél y ledije: "iiiYo soy el paaadre, yo soy el paaadre!!!"

D e igual manera están inscritas en las marcas de temporalidad los procesos ideológicos subyacentes a la situación dramática; me refiero a la apropiación de 
la identidad tal como se plantea en los casos de los bebés secuestradosy dados en adopción de manera clandestina durante el gobierno militar argentino $0^{41}$. La situación dramática termina cuando los desconocidos se llevan a Adriana y EI $\mathrm{H}$ ombre gesticula, realiza los movimientos mímicos tal como los recuerda e hiciera en ese entonces.

Tampoco recuerdo cómo llega Ana M aría aquí, lo que sí recuerdo es que la mano derecha de ella está aquí, la mano izquierda mía aquí, así, sí, sí aquí está, la mano, le toma la mano derecha con la izquierda mía, le aprieto la mano, es una ceremonia, un ritual del silencio, del dolor, sin hablar... todo estaba acá, todo estaba acá, jpor D ios!... las manos to cán dose, no había nada que hablar... Y yo descubro: ésta es mi mujer... ésta es mi mujer... Y los dos nos miramos cómo se la llevaban a Adriana...

La figura en análisis (figura bifronte) va a constituirse, mediante la ruptura del tiempo dramático, como figura del poder. El ejercicio del poder se pone en evidencia a través de esta figura que es a la vez sujeto agente y sujeto paciente de éste; este último estado predominante en esta situación.

Ahora bien, siguiendo las reflexiones de Foucault, vemos que lo que define al poder es el modo de actuar sobre las acciones de los otros, en aquellas acciones existentes 0 en aquellas futuras. Asimismo, el autor señala: "La relación de poder sólo puede ser articulada en base a dos el ementos, cada uno de ellosindispensable si es realmente una relación de poder: "el otro" (aquel sobre el cual es ejercido el poder) ampliamente reconocido y mantenido hasta el final como la persona que actúa; y un campo entero de respuestas, reacciones, resultados y posibles invenciones que pueden abrirse, el cual está enfrentando a una relación de poder"42. Consecuentemente plantea que la puesta en escena de estas relaciones de poder no excluyen el uso de la violencia, ni la obtención del consentimiento y es en la coexistencia de ambos estados donde el ejercicio del poder existet3.

41 "El 24 de marzo de 1976 un golpe de Estado de las Fuerzas Armadas interrumpió al gobierno constitucional para imponer una política de terror y avasallamiento de los derechos sociales e individuales del pueblo de la República Argentina. El saldo de este accionar delictivo fue la desaparición de miles de opositores políticos a los que les esperaba la muerte clandestina o la prisión sin el debido proceso. 365 campos de concentración fueron habilitados para ese fin. Esta metodología aberrante también se ensañó con los hijos de los prisioneros, al gunos de corta edad, otros nacidos en esos centros clandestinos durante el cautiverio de sus padres". Carlotto, Estela: El robo deniñosyla impunidad en Argentina, web sitehttp://www. derechos.org

${ }^{42}$ Foucault, M ichel: El sujeto y el poder, web site http://www.campogrupal.com

${ }^{43} \mathrm{El}$ autor continúa: "Pero a pesar de que el consenso y la violencia son los instrumentos o los resultados, ellos no constituyen el principio o la naturaleza básica del poder. El ejercicio del poder puede producir tanta aceptación al punto de ser deseado: puede acumular muerte y cubrirsea sí mismo detrás de cualquier amenaza imaginable. En sí mismo el ejercicio del poder 
Leemos la figura propuesta, entonces, como la escenificación del poder y en tanto ejercicio sistemático de éste (consecuencia psicológica), como escenificación de la angustia. Siguiendo nuevamente el análisis psicoanalítico, la angustia es definida como un "estado de afecto, provocado por una aumento de la excitación que le indicaría al yo la inminencia de un peligro"44. Así, la potestad adquirida sobre la hija transforma la figura anal izada de víctima a sobreviviente. La víctima, en quien el yo se ha desplazado hacia la desapropiación de la propia identidad, teme perder su objeto de amor y va a construir su nueva imagen en la apropiación dela identidad de otra persona; una acción vincularmente factible si pensamos en la fundación de un orden sicológico adecuado para sí mismo. A nivel social-ideológico, el cuerpo social denotado correspondiente al estatuto legal de poder militar, está supedidato al "terrorismo de Estado", elemento que le indica la misma ansiedad por apropiarse de aún más víctimas, proyectándose como lo sobreviviente (superación) de la caída en la ficción marxista (la angustia).

\subsection{El teléfono-contestar la llamada}

Esta situación dramática se inicia con la incorporación a la fábula de un nuevo personaje: "Tita"; que es amiga del personaje monologante, El Hombre. La irrupción deT ita se genera como un momento de simultaneidad entre la enunciación de la fábula y la historia referida. Tita entra en escena y se sitúa atrás de El Hombre:

Entra Tita, colocándose detrás de él. A partir de aquí y durante ciertos momentos de la obra los dos personajes sentados en ambas sillas realizan movimientos con las sillas.

La relación que establecen ambos personajes, en términos comunicativos, es en apariencia monológica, sin embargo, asistimos a un grado de monologismo en el cual el sujeto único de enunciación ha estado hablando consigo mismo y por lo pronto se apresta a hablar con un personaje fantasmal. El H ombre relata a T ita sus sentimientos sobre la ida de Adriana y de cómo él y su esposa habían deseado largamente un embarazo que nunca se concretó. A través de la noción

no es violencia, tampoco es consentimiento, queimplícitamentees renovable. Es una estructura total de acciones traídas para al imentar posibles acciones; él incita, induce, seduce, hace más fácil o más difícil, en el extremo, él constriñe o prohíbe absolutamente; es a pesar de todo siempre una forma de actuar sobre un sujeto o sujetos actuantes en virtud de sus actuaciones o de su capacidad de actuación. Un conjunto de acciones sobre otras acciones". Foucault, op. cit.

${ }^{44}$ Kaufmann, op. cit., p. 61. 
de maldad, este personaje intenta dilucidar las circunstancias psicológicas y sociales de su actual relación con la realidad.

Yo pensaba que la maldad era cosa abstracta, iteórica! Pero cuando la veo encarnada en personas de carne y hueso, que gritan, se ríen, gesticulan, insultan y persiguen, como si hubieran nacido para eso, iipara perseguir!! M e siento tan solo, Tita... Es muy difícil explicarte, Tita, el vacío inenarrable que se siente... Vos sabés que en estos momentos...

Leo este intento de revelación como un estado de proyección psicológica, en el cual la relación con la realidad ha sido asimilada por introyección. El desplazamiento del yo hacia el exterior encubre la profunda alteración que marcó al país argentino durante el "período de muerte" 45 . Sin embargo, para la comprensión del fenómeno de la maldad es necesaria la explicación de la metáfora de la figura bifronte, antes mencionada.

H uneeus plantea que no es posible dividir a la humanidad entre aquéllos potencialmente malignos y los que no; sino que necesariamente implica un entrenamiento psicosocial que activa diferentes mecanismos de defensa en el sujeto para incorporarse como sobreviviente en un ambiente alterad $0^{46}$. U no de estos mecanismos de defensa es el desdoblamiento de sí mismo, el cual se genera al asimilar una realidad que es ajena e implica la división del sí mismo en dos totalidades, las quefuncionan como un sí mismo en totalidad. A hora bien, "lo crítico del desdoblamiento essu dialéctica entre la autonomía y la conexión que existeentre ambos sí mismos"47.

45 “El 24 del marzo en 1976 una junta militar se hizo cargo de la dirección en la Argentina y lanzo una campaña militar para destruir el terrorismo izquierdista. La junta ocasionó más terror que el terror que estaba combatiendo. Entre 1976 y 1983, durante el dominio militar, unas treinta mil personas fueron arrestadas y se desaparecieron". Las madres de la Plaza de M ayo, web site http://www.madres.org

${ }^{46} \mathrm{El}$ autor señala: "Lo cierto es que la humanidad no se divide nítidamente entre aquellos que tienen la potencialidad de producir el mal y los que no. $\mathrm{H}$ ay más bien un continuum. Se puede suponer que los hombres que cometieron esos crímenes, 0 aquellos que después continuaron con el encubrimiento, en otras situaciones no se habrían ganado el calificativo que merecerían de caracteres malignos. Lo más probable es que sean buenos ciudadanos, observantes religiosos algunos, padres de familia la mayoría, apoyadores de su comunidad". H uneeus, Francisco y Sandra Isella: Los orígenes psicológic cos de la maldad grupal en lasFF.AA. y de O rden: Necesidad de una continua revisión (Trabajo presentado al Concurso de la Comisión de Reconciliación y Justicia, Chile, 1996), web site http://www.campogrupal.com

${ }^{47} \mathrm{H}$ uneeus continúa: "El desdoblamiento es un mecanismo adaptativo extremo, impulsado sólo por circunstancias extremas. Se activa mediante la experiencia de la muerte o frente a 'equivalentes dela muerte' como el temor a la desintegración física o psíquica, el aislamiento 0 la parálisis total y equivalea "una forma de supervivencia psicológica en un ambiente dominado por la muerte" (... ). "Al mismo tiempo el desdoblamiento implica evitación dela culpa y alteraciones muy significativas de la propia percatación y de la conciencia moral". H uneeus, op. cit. 
En este sentido, el personaje El H ombre como figura dinámica en la que se desplaza la conciencia de sí mismo y que repudia a otra parte de sí, ha elegido apropiarse de la identidad de Adriana, pero no interpreta tal elección como aberrante, ya queel repudio es la base vital del sí mismo. Como consecuencia proyecta en el "otro" queya repudia en él, la causa y concreción del mal; se representa ante sí mismo una escena de autoengaño, en la cual la mentira, la simulación y la negación de la autocrítica son esquivados de la conciencia moral ${ }^{48}$.

A su vez, el personajefantasmal, Tita, se desarrolla como una figura especuIar; ella presentifica a la conciencia de sí mismo de El H ombre y luego al objeto de amor, es decir, se pone en escena la compleja alteración del yo, que se desencaja de lo real y se somatiza en ella: el personaje grita, se levanta de la silla, se sienta, evita la mirada de EI H ombre, etc.

0 tro elemento que interviene en esta situación dramática es el teléfono. A través de este aparato se canaliza el afecto paranoico, mencionado en la primera situación dramática; el personaje masculino está a la espera de una llamada telefónica en la cual su hija, Adriana, se va a comunicar con él, pero paradójicamente suena el teléfono, contesta y nadie responde al otro lado.

El otro día sonó el teléfono, dos veces, no contestaron. Ana M aría pensó que era la nena, Tita, que no la dejaban hablar... pero que en cambio podía escuchar... Se puso como loca, Tita... “ ¡N ena!, ipor Dios! Te están haciendo algo, te están pegando, yo estoy aquí con papá, te quiero mucho, hija... " 'Se estaba volviendo loca, T ita! Yo le saquéel teléfono: “ ¡H ola, Adriana! ¡Aquí están papá y mamá, hija! ¡N o hables, escucha! ¡N o hables, hija! Adriana, mamá y papá están aquí rezando, rezando por vos..."

El teléfono como objeto que ha dejado de ser funcional, lo leo como una figuración de los procesos obsesivos en el cual convergen los tiempos de rememoración y la predictibilidad de un futuro. Ya no hay otra forma de entrar a la realidad sino que desde el sueño, como estado intermedio entre el recuerdo y lo imaginario. Asimismo, la relación de El H ombre consigo mismo está ya lo suficientemente afectada por la sobrecargada presentificación de todos sus afectos: la figuración de la víctima (afecto paranoico), la figuración del poder (afecto de angustia), la figuración de la maldad (afecto obsesivo); y la activación de los

${ }^{48} \mathrm{El}$ autor señala: "N inguno de estos autores (Scott Peck y D e Lifton) opina que hay una ausencia de la conciencia moral, sino más bien una 'transferencia de la conciencia' donde los requisitos de ésta se desvinculan de los valores e ideales del concepto original del sí mismo y se adhieren a los ideales del sí mismo desdoblado (como el de la 'sanación racial' del nazismo, o el aniquilamiento 'del marxismo-leninismo'), con el resultado que la percatación del significado moral del asesinato y la tortura de los perpetradores se sumerge bajo una declarada lealtad a causas más altas y nobles. O bviamente, ésta es la perversión dela conciencia". H uneeus, op. cit. 
diferentes mecanismos de defensa desplegados, los cuales desembocan en la metamorfosis de éste y se pone en escena la figuración de la muerte.

M e doy cuenta de que estoy soñando, pero me hago trampas, Tita, trato de pensar que es realidad, que no es un sueño, para retener la imagen de la nena tres segundos, nada más que tres segundos... para verle la cara unos instantes, nada más que unos instantes. (... ) ¡Es Ana! ¡Shhh! ¡Shhh! ¡Es Ana! (Se dirige hacia la pared posterior, donde se coloca bruscamente en posición de "cacheo" policial con los brazos y las manos abiertas apoyadas tocando la pared. Al darse vuelta aparece transformado en un burdo personaje fascista, con las manos en la cintura. El proceso de metamorfosis es casi grotesco. Lentamente vuelve al "personaje" anterior y se sienta para reanudar el diálogo con Tita. Al reanudar el diálogo con Tita algo del personaje fascista se debe apreciar sutilmente en la actuación).

El personaje El H ombre ha vaciado su yo en escena, ha roto el espejo de su identidad, de manera que no encubre su rostro y muestra su maldad. Esta maldad es la síntesis de su historia personal en la queha introyectado la ideología de la aniquilación, según la cual el asesinato y la tortura del otro es una conditio sine qua non que asegura la propia conservación, demonizando y deshumanizando a quien procede de otro modo.

¡El papá y la mamá de Adriana eran fanáticos, Tita! iA estos hijos demil putas, si no los cagaban a balazos en la cama te cagaban ellos, te hacían volar la casa... ! Estaban ahí... yo me acerquéa la cama... eran jóvenes...

En su diálogo con Tita, El H ombre ha rememorado el episodio núcleo de la intriga: el se desempeñaba como médico y había sido llamado para certificar la muerte de "dos fanáticos"; al momento en que realiza la constatación escucha un llanto en otra de las piezas de la casa y ve a una niña, la toma y la traslada a su propia casa.

Los muchachos me llamaron para ver si estaban vivos. Fue un domingo en la tarde, en la calle Amenábar 2030, me puse el guardapolvo blanco (... ) Llegué a las cinco de la tarde ahí, toqué el timbre, apareció uno de los muchachos, lleno de sangre, con el arma en la mano, y me dijo: "BBuenas tardes, doctor!" " ¿Sí?" "Q ueremos que usted certifiquesi esta señora ha fall lecido, porquehasta hace poco estaba gritando"... (...) El cuarto estaba todo lleno de sangre. $\mathrm{H} \mathrm{a-}$ bía sangreen la puerta, en el piso, en el techo, en las ventanas. (... ) M edejaron solo. Escuché como un Ilanto, T ita, en el cuarto deal lado... abrí la puerta y vi a la nena... hijos de puta! fienen a la nena acá! hijos de puta! jestaba la nena acá.! 
Consecuentemente, el personaje resuelve la frustración de no haber podido tener hijos en la figura de Adriana.

Por D ios, jun milagro de D ios!, jtantosaños esperando, graciasa D ios... ! ¡Q uién te va a cuidar a vos más que yo y Ana M aría, que estuvimos esperán dote tantos años! Agarré a la nena y la puse en el coche y la nena me miraba con esos ojos celestes, la nena me miraba y se la llevé a Ana, y Ana abrió la puerta. jAna! ¡Ana! No digas nada, esta nena es nuestra, Ana, esta nena es... no preguntes nada, no preguntes nada... ime la gané yo, yo, yo! Esta nena es nuestra, me la gané. ¡Yo! ¡Yo! iiiEs nuestra!!! ijShhhh Shhh!! No preguntes nada. N unca preguntes nada. N unca más preguntes nada. N unca más.

La figuración de la muerte, que se sustenta en la estructura ideológica de quien la relata, organiza y distribuye los roles a ser actuados. Convierte a través de las pulsiones de agresión y de crueldad los episodios de ternura en episodios hostiles y pone en escena una nueva figura, hija de su simbolismo, la figuración dela violencia. Asimismo, la violencia va a ser eficaz en la medida que es posible advertir hasta qué punto se ejerce, hasta qué punto se está haciendo morir; porque llega un momento en el cual el sujeto que es violentado sistemáticamente se anestesia y se genera la desconexión con el sufrimiento, es entonces cuando ya no tiene sentido seguir violentado, torturando, asesinando, porque se ha perdido la conciencia reflexiva del yo.

Leo en esta forma particular de ejercer la violencia, una sintomatología del terror que determina la experiencia histórica de una sociedad, que aún no resuelve los desplazamientos de su yo social. Los contenidos sensoriales silenciados se han vuelto sobresí nuevamente, dejando expuesto el trauma queangustia el cuerpo psicosocial; estos contenidos sehan transmitido intergeneracionalmente a través de los gestos, los movimientos, sin la mediación de las palabras, siendo atesorados en la memoria colectiva como si se hubieran vivido.

Exorcizar el trauma a través del relato del horror es en primera instancia un ejercicio crítico de asir lo social; presenciar en escena su dinámica es integrar los fragmentos de ésta para reconstituir la imagen perdida en el dolor y volver a desplazar el yo hacia la cura.

A través del análisis del texto espectacular hemos visto como las relaciones entre los signos sociales y psicológicos configuran una escena material única generadora en tanto clave elaborativa de interpretación de una poética del estupor; es decir, la constitución de una macrofigura dramática - la violencia- comprendida estéticamente en un estado de perturbación y en una práctica ética de la no conformidad. 
Con la figuración de la violencia se nos hacen evidentes tres situaciones dramáticas que a la vez proponen la escenificación de la realidad como la diagnosis de un cuerpo psicosocial traumático, en cuyos desplazamientos dela conciencia de sí mismo se apropia del acontecimiento histórico y lo devela.

La escena material única está equipada por determinados objetos que ope ran como subtexto espacio-temporal. Se lee el texto en su dinámica espectacular. La relación que se establece entre texto dramático y texto espectacular es directa, de manera que la silla, la puerta y el teléfono imprimen significado tanto como dispositivos escénicos, así como en función de las acciones que generan: sentarse, abrir la puerta y contestar el teléfono, respectivamente.

Los procedimientos de disposición temporal - propios del teatro de vanguardia- nos permiten ver la historia en movimiento remitente, la escena inicial de la fábula remite a un episodio anterior al que está siendo evocado, por lo tanto, la construcción de la intriga es fragmentada y depende de los desplazamientos de interioridad de un personaje que se lleva la carga dialógica. Vemos en escena la dinámica interna de nuestra sicología, la manera propia de actuar de nuestros afectos.

Cada situación dramática es un cambio de perspectiva para abordar la macrofigura; en la primera situación dramática, la figura de El Hombre es bifronte, hace presente la figuración de la víctimización según la cual los vínculos familiares se han hecho patológicos y el cuerpo social ha sido arrasado por los fantasmas de la muerte.

En la segunda situación dramática, se concretala cualidad de bifrontismo de la figura El H ombre, al escenificar el ejercicio particular que éste hace del poder, es decir, la patria potestad de una identidad otra que no le pertenece. Así, se ponen en evidencia los diferentes mecanismos de defensa que la psiquis genera para orientar la conciencia moral de lo aberrante.

En la tercera situación dramática, esta figura se ha vaciado de sí misma en la puesta en escena de sus fantasmas, los que se han hecho presentes en la figura de Tita y que muestran el rostro real de quien los invoca: esla presentificación dela maldad, que en tanto ideología del aniquilamiento se comporta como figuración de la muerte.

Finalmente, en un intento de vincular la percepción estética y la ideológica que subyace a la lectura propuesta, leo el texto espectacular como la ficcionalización de un acontecimiento histórico que en su calidad de teatral (dispositivos escénicos) reduce el terror de lo inasible o de una situación temida y demanda actos de descubrimiento, actos de reflexión, actos de terapia. 


\section{REFEREN CIAS BIBLIOGRAFICAS}

Avelar, Idelber. 2000. "Una lectura alegórica de la tradición argentina", La ficción posdictatorial y el trabajo del duelo, Santiago: Editorial Cuarto Propio, pp. 123-150.

Carlotto, Estela. El robo de niños y la impunidad en Argentina, web site http://www. derechos.org

Carpintero, Enrique. "La cultura del mal-estar: El sujeto es el planeta". Registros de lo negativo, Topia, web site http://www.topia.com.ar

Contreras M arta. 1994. G risedda Gambaro. Teatro dela descomposición, Concepción: Ediciones Universidad de Concepción.

Corominas, Joan. 1976. Diccionario crítico etimológico de la lengua castellana, M adrid: Editorial Gredos.

Costa, Ivana. 2000. “Un nombre propio para huir de la nada”, Clarín Espectáculos (2 de agosto), web site http:// www.laguia.clarin.com

Costa, Ivana. 2001. "Teatro: Inteligencia y coraje para combatir la censura. Una abierta resistencia", Clarín (24 de marzo), web site http://www.laguia.clarin.com

D eToro, Alfonso. 1996. "D as postmoderne Theater von Eduardo Pavlovsky". M aske \& Kothurn 1, web site: http://www.uni-leipzig.de/ -detoro

Foucault, M ichel. El sujeto y el poder, web site http://www.campogrupal.com

H uneeus, Francisco y Sandra I sella. 1996. Los orígenes psicológicos de la maldad grupal en las FF.AA y de O rden: Necesidad de una continua revisión (Trabajo presentado al Concurso de la Comisión de Reconciliación y Justicia), Chile, web site http:// www.campogrupal.com

Itzcovich, M abel. 2001. "La ciudad premió al teatro", Clarín Espectáculos (19 de julio), web site http://www.laguia.clarin.com

Kaufmann, Pierre (director). 1996. Elementos para una enciclopedia del psicoanálisis. El aporte freudiano. Buenos Aires: Paidós.

Kesselman, H ernán y Eduardo Pavlovsky. 2000. La multiplicación dramática. Buenos Aires: Editorial Galerna.

Las M adres de la Plaza de M ayo, web site http://www.madres.org

Pavis, Patrice. 1998. Diccionario del teatro. D ramaturgia, estética, semiología. Editorial M adrid: Paidós.

Pavlovsky, Eduardo y Armando Bauleo. 1976. Psi coterapia en situaci onesexcepcionales, web site http://www.campogrupal.com

Pavlovsky, Eduardo. 1982. Reflexiones sobre el proceso creador, Buenos Aires: Ediciones Búsqueda.

---_-_- 1982. Terapia y existencia, Buenos Aires: Ediciones Búsqueda.

1983. Lo fantasmático social y lo imaginario grupal, web site http:// www.campogrupal.com

-..-_._- 1992. "Potestad", Teatro argentino contemporáneo. Antología (Gerardo Fernández, coordinador), M adrid: Editorial Fondo de Cultura Económica. pp. 781795.

. . 1992. Teatro del '60, Buenos Aires: Ediciones Letra Buena.

1998. "M icropolíticas éticas", revista L ote N 014 (agosto), web site http://www.revistalote.com.ar

. http://www.topia.com.ar 
web site: http://www.campogrupal.com/textos.html

Pavlovsky, Eduardo, James Petras y D avid Viñas. "El lenguaje imperial, los intelectuales y la izquierda" (C onferencia), revista H erramientas, web site http://www.herramienta. com.ar

Q uiroga, O svaldo. 1992. "El teatro de Eduardo Pavlovsky", Teatro de '60, Buenos Aires: Ediciones Letra Buena, pp. 7-11.

Sociedad Argentina de Escritores (Argentores). Eduardo Pavlovsky, web site http:// www. autores.org.ar/Epavlovsky

"Un teatro de incertidumbres" (Entrevista), Clarín Cultura y Nación (13 de agosto de 2000), web site http://www.laguia.clarin.com

Zunino, Pablo. 1992. "Lasheridas del horror", Teatro argentino contemporáneo. Antología. $M$ adrid: Fondo de Cultura Económica. 